\title{
The Role of Chlamydial Endometritis in the Pathogenesis of Perimenopausal Bleeding
}

\author{
Sakna NAES ${ }^{1 *}$ and Howeidy $\mathrm{II}^{2}$ \\ ${ }^{1}$ Department of Obstetrics and Gynecology, Ain Shams \\ University, Abbasyia, Egypt \\ ${ }^{2}$ Department of Clinical Pathology and Microbiology, Ain \\ Shams University, Egypt \\ *Corresponding author: Noha Abd El-Sattar Sakna, \\ Department of Obstetrics and Gynecology, Ain Shams \\ University, Abbasyia, Egypt
}

Received: November 05, 2017; Accepted: December 04, 2017; Published: December 11, 2017

\begin{abstract}
Objective: The goal of this study is to evaluate the prevalence of Chlamydial endometritis in women with perimenopausal bleeding presented at Ain Shams University Maternity Hospital outpatient clinics.

Design: A cross-sectional study. Setting: Ain Shams Maternity University Hospital. Patients and methods: 150 consented women were divided into two equal groups of 75 women in each one. Intervention: patients admitted through the reception room or out-patient clinics (hospital department) and they scheduled for Pipelle endometrial samples. Group I saught medical advice because of peri-menopausal bleeding while group II were attending the hospital due to any other cause other than vaginal bleeding. Pipelle endometrial biopsy was taken and sent for detection of Chlamydia trachomatis by PCR. Results: In group I, 82 specimens were positive for Chlamydia and the other 68 specimens were negative for Chlamydia while in group II only 22 specimens were PCR positive for chlamydia. There was a statistical significant correlation between positive cases of $C$. endometritis and Abnormal Uterine Bleeding (AUB).
\end{abstract}

Conclusion: screening for Chlamydia trachomatis in patients with perimenopausal bleeding is recommended.

Keywords: Chlamydia trachomatis; Menorrhagia

\section{Introduction}

Abnormal Uterine Bleeding (AUB) in peri-menopausal age group is a common but ill-defined entity which needs proper evaluation. Goldstein et al [1] has defined AUB as "Patients having either metrorrhagia defined as vaginal bleeding separated from expected menses or menorrhagia defined as patients' subjective complaints of either increased duration or increased volume of flow or both". In general, women present themselves to the gynecologists whenever there is a departure from their personal menstrual experiences. Variations from the normal cyclical pattern in the peri-menopausal age may be due to physiological hormonal changes on one hand or may be due to neoplastic changes either benign or malignant, on the other hand. Therefore, accurate diagnosis of the causative factor of AUB in this age group is of utmost importance so that appropriate management can be established. Tests have evolved over the years starting from blind Dilatation \& Curettage (D\&C), to latest immune histo chemical markers [2].

Endometritis presents clinically by elevated temperature, uterine tenderness, vaginal bleeding, leukocytosis, or positive endometrial cultures. Clinically evident endometritis is usually presented in the setting of acute PID or postpartum or post abortive [3]. Due to its subtle clinical picture, the true incidence of this pathology among women is unclear, with estimates ranging from $0.8 \%$ to $19.0 \%$. $72 \%$ of histologic samples gathered from women asking care in STD clinics, were positive [4].

Chlamydia trachomatis (C. trachomatis) is the most frequent sexually transmitted bacterium [5]. Lower genital tract infection by this organism is usually asymptomatic in men and women, 50-66\% of such infections in women remain undiscovered and consequently untreated, and leading to undesired long-term effects, ectopic pregnancy and tubal infertility are outstanding examples [6]. Hence, screening is needed to detect and manage this infection to decrease the period of infectivity, transmissibility and future adverse effects [7].

As culture techniques are hard to standardize, technically exhausting and not cheap, other tests have been arised [8]. Nucleic Acid Amplification Techniques (NAAT) are now being utilized to diagnose chlamydial infections. NAATs are used with noninvasively gathered samples, such as First-Void Urine samples (FVU) from men or women and vaginal smears leading to increased compliance of $C$. Trachomatis screening programs among asymptomatic persons [9].

In a Cochrane review, the mean prevalence of endometritis was $7 \%$ after elective cesarean section and 30\% after nonelective or emergency cesarean section [10]. CE is characterized by plasma cell infiltration in the endometrium [11]. Most of the time CE is accidentally discovered after an endometrial biopsy or a Dilatation and Curettage $(\mathrm{D} \& \mathrm{C})$ for different indications such as abnormal vaginal bleeding, postmenopausal bleeding, endometrial polyps, etc.

Accurate estimates of incidence data for Chlamydial infection of the female genital system using sensitive and specific methods like nucleic acid amplification tests are lacking in developing countries as Egypt. Few available data describe an increased incidence of infection, especially among symptomatic Egyptian women [12]. There is an ongoing debate as to whether or not screening of all women with menorrhagia and management of those diagnosed to be infected
Austin J Obstet Gynecol - Volume 4 Issue 4 - 2017

Submit your Manuscript | www.austinpublishinggroup.com

Sakna et al. @ All rights are reserved
Citation: Sakna NAES and Howeidy II. The Role of Chlamydial Endometritis in the Pathogenesis of Perimenopausal Bleeding. Austin J Obstet Gynecol. 2017; 4(4): 1084 
is needed or cost effective. The goal of this study is to evaluate the prevalence of Chlamydial endometritis in women with menorrhagia and answer the question to screen or not to screen.

\section{Patients and Methods}

This was a cross-sectional study performed in A in Shams Maternity University Hospital involving 150 women; a first group 75 cases with perimenopausal bleeding and a control group of 75 perimenopausal women with normal menstruation attending gynecologic outpatient clinic (hospital department), for any reason other than bleeding. Pipelle endometrial biopsies were collected and sent for detection of Chlamydia trachomatis by PCR. This study was carried out in the period from January 2014 to December 2015 and it was approved by Ethical Committee of the Faculty of Medicine, Ain Shams University. Explanation of the procedure and verbal consent was taken for every patient.

\section{Inclusion criteria}

1. Perimenopausal females; age 40-50 years.

2. Complain of dysfunctional uterine bleeding.

3. No gross uterine lesions were detected by vaginal US.

4. Women who live in Cairo

\section{Exclusion criteria}

1. Patients who are immediately post partum or post abortion or known cases of sexually transmitted diseases.

2. Patients with any uterine abnormality detected by transvaginal sonar or hysteroscopy.

3. Patients with suspicion of pregnancy or malignancy.

4. Women who live outside Cairo.

\section{All patients were subjected to}

1) Full history taking, complete physical examination.

2) Counseling and verbal consent was taken for every patient.

3) Pipelle endometrial biopsies were taken and sent to confirm Chlamydia trachomatis endometritis by PCR.

\section{Endometrial biopsy}

Transport medium: 2-sucrose phosphate buffer (PH 7.0) supplemented with $5 \%$ fetal bovine serum, 50ug of streptomycin/ $\mathrm{ml}$, 100ug of vancomycin per $\mathrm{ml}$ and $12.5 \mathrm{ug}$ of amphotericin B (Fungizone) per $\mathrm{ml}$ (Phosphate Buffer Saline).

\section{Detection of the C. Trachomatis DNA in the collected specimens by}

Extraction of DNA: This was performed using the QI Amp DNA mini kit (QIAGEN GmbH, Hilden, Germany Cat. No.51304) as described by the manufacturer.

Real-time PCR assay: According to Jaton and her colleagues, A forward primer Ctr_F (5'-CATGAAAACTCGTTCCGAAATAGAA-3'), a reverse primer Ctr_R (5'-TCAGAGCTTTACCTAACAACGCATA-3') (which amplify a 71 bp DNA segment of C. trachomatis) and a minor-groove binder probe labeled with 5'FAM (6-carboxyfluorescein) Ctr_P
Table 1: Clinic-demographic data of the population under study.

\begin{tabular}{|c|c|c|c|}
\hline & Group I & Group II & P-value \\
\hline Age & $46.7 \pm 4.8$ & $46.3 \pm 3.9$ & $>0.05$ \\
\hline Body mass index (kg/m²) & $31.4 \pm 3.6$ & $32.1 \pm 3.1$ & $>0.05$ \\
\hline Previous gravidity & $4 \pm 1.2$ & $3.8 \pm 1.4$ & $>0.05$ \\
\hline Previous parity & $3.2 \pm 0.3$ & $3 \pm 0.1$ & $>0.05$ \\
\hline Duration of marriage & $23.8 \pm 2.8$ & $24.3 \pm 2.5$ & $>0.05$ \\
\hline Frequency of coitus per week & $3.1 \pm 0.4$ & $2.9 \pm 0.2$ & $>0.05$ \\
\hline \multicolumn{4}{|l|}{ Mode of delivery } \\
\hline Vaginal & 52 & 49 & $>0.05$ \\
\hline Cesarean & 23 & 26 & \\
\hline \multicolumn{4}{|l|}{ Education } \\
\hline$\leq$ High school & 27 & 23 & $>0.05$ \\
\hline >High school & 48 & 55 & \\
\hline \multicolumn{3}{|l|}{ Occupation } & \multirow{4}{*}{$>0.05$} \\
\hline House wife & 61 & 59 & \\
\hline Employed/business & 14 & 16 & \\
\hline \multicolumn{3}{|l|}{ Woman } & \\
\hline Previous use of IUCD & 59 & 52 & $>0.05$ \\
\hline Previous use of hormonal contraception & 62 & 65 & $>0.05$ \\
\hline
\end{tabular}

Table 2: Number and percent of positive cases for $C$. trachomatis by PCR.

\begin{tabular}{|c|c|c|c|}
\hline & Group I & Group II & P value \\
\hline Positive cases & $44(58.7 \%)$ & $17(22.7 \%)$ & $<0.05$ \\
\hline Negative cases & $31(41.3 \%)$ & $58(77.3 \%)$ & (significant) \\
\hline
\end{tabular}

Table 3: Correlation between age and presence of Chlamydia in the two groups with no significant correlation.

\begin{tabular}{|c|c|c|c|c|c|c|}
\hline \multirow{2}{*}{ Age (years) } & \multicolumn{5}{|c|}{ PCR of Chlamydia } \\
\cline { 2 - 7 } & \multicolumn{2}{|c|}{ Negative } & \multicolumn{2}{|c|}{ Positive } & \multicolumn{2}{c|}{ Total } \\
\cline { 2 - 7 } & No. & $\%$ & No. & $\%$ & No. & $\%$ \\
\hline $40-45 \mathrm{y}$ & 42 & 28 & 29 & 19 & 71 & 47 \\
\hline $45-50 \mathrm{y}$ & 47 & 31 & 32 & 21 & 79 & 53 \\
\hline Total & 89 & 59 & 61 & 41 & 150 & 100 \\
\hline P-value & & \multicolumn{5}{|c|}{$>0.05$} \\
\hline
\end{tabular}

(5'-TCGCATGCAAGATATCGA-3') were selected. The Melting Temperature (Tm) of the probe was chosen to be $10-11^{\circ} \mathrm{C}$ higher than that of the corresponding primers. The reactions were performed in a final volume of $20 \mu \mathrm{l}$, including $0.2 \mu \mathrm{M}$ each primer, $0.1 \mu \mathrm{M}$ Ctr_P probe, $10 \mu \mathrm{l} 2 \mathrm{x}$ Taq Man Universal Master Mix (Applied Bio systems) and $5 \mu \mathrm{l}$ DNA sample. Cycling conditions were $2 \mathrm{~min}$ at $50^{\circ} \mathrm{C}, 10$ min at $95^{\circ} \mathrm{C}$, followed by 45 cycles of $15 \mathrm{~s}$ at $95^{\circ} \mathrm{C}$ and $1 \mathrm{~min}$ at $60^{\circ} \mathrm{C}$. Amplification and PCR product detection were performed with the One Step Sequence Detection system (Applied Biosystems) [13].

Each run included the testing of the positive and negative extraction control lysates, Tris-EDTA buffer in four reactions (no-template controls), and diethyl-pyrocarbonate-treated water (QIAGEN Germany) in duplicate reactions (negative reagent controls). The no-template controls and negative reagent controls were used to detect any nonspecific fluorescent signal or carry-over 
Table 4: Correlation between parity and presence of Chlamydia in the patients with no significant correlation.

\begin{tabular}{|c|c|c|c|c|c|c|}
\hline \multirow{2}{*}{ Parity } & \multicolumn{5}{|c|}{ PCR of Chlamydia } \\
\cline { 2 - 7 } & \multicolumn{2}{|c|}{ Negative } & \multicolumn{2}{|c|}{ Positive } & \multicolumn{2}{c|}{ Total } \\
\cline { 2 - 7 } & No. & $\%$ & No. & $\%$ & No. & $\%$ \\
\hline 3-Jan & 45 & 30 & 30 & 20 & 75 & 50 \\
\hline 4 or more & 44 & 29 & 31 & 21 & 75 & 50 \\
\hline Total & 89 & 59 & 61 & 41 & 150 & 100 \\
\hline P-value & & \multicolumn{7}{|c|}{$>0.05$} \\
\hline
\end{tabular}

Table 5: Correlation between the form of abnormal uterine bleeding (AUB) and presence of Chlamydia in the patients with no significant correlation.

\begin{tabular}{|c|c|c|c|c|c|c|}
\hline \multirow{2}{*}{ Uterine bleeding } & \multicolumn{5}{|c|}{ PCR of Chlamydia } \\
\cline { 2 - 7 } & \multicolumn{2}{|c|}{ Negative } & Positive & \multicolumn{2}{|c|}{ Total } \\
\cline { 2 - 7 } & No. & $\%$ & No. & $\%$ & No. & $\%$ \\
\hline Regular & 39 & 26 & 27 & 18 & 66 & 44 \\
\hline Irregular & 50 & 33 & 34 & 33 & 84 & 66 \\
\hline Total & 89 & 59 & 61 & 41 & 150 & 100 \\
\hline P-value & \multicolumn{5}{|c|}{$>0.05$} \\
\hline
\end{tabular}

contamination. Run acceptability required obtaining the expected results from each control. Samples were considered positive if the amplification plots (i.e., change in normalized reporter signal versus PCR cycle number) from duplicate reactions showed definite exponential increase in fluorescent signal. If the fluorescent signal did not increase within 45 cycles, the sample was considered negative.

Statistical methodology: Retrieved data were recorded on an investigative report form. The data were analyzed with SPSS ${ }^{*}$ for Windows $^{\oplus}$, version 15.0 (SPSS, Inc, USA). Description of quantitative (numerical) variables was performed in form of mean, Standard Deviation (SD) and range. Description of qualitative (categorical) data was performed in the form of numbers and percent. Analysis of numerical variables was performed by using student's unpaired t-test (for two groups) or ANOVA (for more than two groups). Analysis of categorical data was performed by using Fischer's exact test and Chisquared test. Significance level was set at 0.05 .

\section{Results}

This cross sectional study involved 150 women consented to participate in this study; group I (test group) of 75 cases with perimenopausal bleeding and group II (control group) of 75 perimenopausal women with normal menstruation recruited from gynecologic outpatient clinic (hospital department), and complaining from any reason other than bleeding. Pipelle endometrial biopsies were collected and sent for detection of Chlamydia trachomatis by PCR. Both groups were comparable in terms of age, body mass index, gravidity, parity, duration of marriage, frequency of coitus per week, mode of delivery (vaginal or cesarean), level of education $(\leq$ High school or $>$ High school), occupation (house wife or employed/ business woman) and previous use of IUCD or hormonal methods and (Table 1-4).

The 150 specimens were sent for detection of Chlamydia trachomatis by PCR. In group I, 44 (58.7\%) specimens were positive for Chlamydia and the other $31(41.3 \%)$ specimens were negative for
Table 6: Correlation between history of abortion and presence of Chlamydia in the patients with no significant correlation.

\begin{tabular}{|c|c|c|c|c|c|c|}
\hline \multirow{2}{*}{ History of abortion } & \multicolumn{5}{|c|}{ PCR of Chlamydia } \\
\cline { 2 - 7 } & \multicolumn{2}{|c|}{ Negative } & Positive & \multicolumn{2}{|c|}{ Total } \\
\cline { 2 - 7 } & No. & $\%$ & No. & $\%$ & No. & $\%$ \\
\hline Positive & 40 & 27 & 32 & 21 & 72 & 48 \\
\hline Negative & 49 & 33 & 29 & 19 & 78 & 52 \\
\hline Total & 89 & 59 & 61 & 41 & 150 & 100 \\
\hline P-value & \multicolumn{7}{|c|}{$>0.05$} \\
\hline
\end{tabular}

Table 7: Correlation between infertility and presence of Chlamydia in the patients with no statistical significant correlation.

\begin{tabular}{|c|c|c|c|c|c|c|}
\hline \multirow{2}{*}{ Infertility } & \multicolumn{5}{|c|}{ PCR of Chlamydia } \\
\cline { 2 - 7 } & \multicolumn{2}{|c|}{ Negative } & \multicolumn{2}{c|}{ Positive } & \multicolumn{2}{c|}{ Total } \\
\cline { 2 - 7 } & No. & $\%$ & No. & $\%$ & No. & $\%$ \\
\hline Fertile & 52 & 35 & 32 & 21 & 84 & 56 \\
\hline Primary & 23 & 15 & 19 & 13 & 42 & 28 \\
\hline Secondary & 14 & 9.3 & 10 & 6.7 & 24 & 16 \\
\hline Total & 89 & 59 & 61 & 41 & 150 & 100 \\
\hline P-value & & \multicolumn{7}{|c|}{$>0.05$} & & \\
\hline
\end{tabular}

Table 8: Correlation between duration of marriage and presence of Chlamydia in the patients with no statistical significant correlation.

\begin{tabular}{|l|c|c|c|}
\hline \multirow{2}{*}{} & \multicolumn{2}{|c|}{ PCR of Chlamydia } & \multirow{2}{*}{ P-value } \\
\cline { 2 - 3 } & Negative & Positive & \multirow{2}{*}{ P-valu } \\
\cline { 2 - 3 } & Mean \pm SD & Mean \pm SD & \\
\hline Duration of marriage & $24.9 \pm 8.43$ & $25.80 \pm 8.19$ & $>0.05$ \\
\hline
\end{tabular}

Chlamydia while in group II only $17(22.7 \%)$ specimens were PCR positive for chlamydia. There was a significant difference between the two groups as regards the incidence of C. trachomatis among symptomatic perimenopausal women complaining of dysfunctional uterine bleeding (Table 4-8).

There was no statistically significant correlation between the presence of chlamydial endometritis and the age of participants, parity, form of bleeding, history of abortion, type of infertility and duration of marriage.

\section{Discussion}

The goal of Chlamydia Trachomatis screening programs is to limit the morbidities from upper genital tract effects and the incidence of the infection by controlling its spread [14]. Moreover, pre-existing silent disease can spread more when patients undergo uterine instrumentation for further assessment and management of their problems. So, the Royal College of Obstetricians and Gynecologists advise that all patients undergoing uterine instrumentation should be screened for Chlamydia or should receive prophylactic antibiotics [15].

In Egypt and most Arab nations, the incidence of sexually transmitted diseases in general and Chlamydial genital infection in particular is not exactly known, reflecting the deficient specific diagnosis and management protocols. Different small studies from various countries showed different prevalences of C. Trachomatis 
infection; United Arab Emirates (2.6\%) [16], Jordan (3.9\%) [17], Qatar (5.3\%) [18], Saudi Arabia (15\%) [19]. This difference in prevalence is linked to age of the individuals under study, as well as the different specific techniques utilized for diagnosis.

Chronic Endometritis (CE) is a subtle pathology which is hard to both diagnose and manage [20,21]. Chronic endometritis is usually clinically asymptomatic, but may be associated wild mild complaints including chronic pelvic pain, abnormal uterine bleeding, painful coitus and leucorrhea [22]. The presence of an inflammatory infiltration containing plasma cells is usually pathognomonic to chronic endometritis. Hence, it cannot be excluded an endometritis if, besides infiltration, there are factors such as attacking behavior against endometrial glands, the presence of an exudates inside gland lumina or the formation of granulomas [23].

The purpose of this study was to determine the prevalence of $C$. trachomatis in endometrial tissues of patients with perimenopausal bleeding. The use of PCR technology is the most currently accepted method for diagnosing endometrial tissue for C. trachomatis antigen and has been validated [24,25]. Nucleic acid amplification has a high sensitivity (90-97\%) and specificity (99\%). The samples are suitable for testing several days after collection, even if kept at room temperature [26-28]. Actually, Ain Shams University Teaching Hospital is one of the biggest referral hospitals in Egypt and manages women with any obstetric or gynecological complaint from a large geographical area so the rates were nonetheless striking.

In the current study, the $C$. trachomatis infection was detected in 44 cases $(58.7 \%)$ in patients with perimenopausal bleeding and 31 cases $(41.3 \%)$ were negative for chlamydia. In a similar study, that included 2,190 diagnostic hysteroscopies, histologic diagnosis of CE was made in 388 cases, it is found that several bacteria can cause CE, the most common among them E. coli, Streptococci, Staphylococci, Enterococcus fecalis, and Yeast species. C. trachomatis and Ureaplasma urealyticum were isolated in only a small proportion of the patients with a histologic diagnosis of $\mathrm{CE}$ in this study. Regarding the type of infectious agent, it is worthy underlining that at the endometrial level the most frequent agents found were common bacteria, accounting for about $60 \%$ of Cases; $U$. urealyticum was detected in $10 \%$ of cases. Unexpectedly, Chlamydia was demonstrated in only $2.7 \%$ of positive endometrial cultures. No cases of N. gonorrhea were found; this in partial agreement with the currnet study (13.3\% of cases) [28].

At the endometrial level, the prevalence of C. trachomatis in our study was higher that reported in the Pelvic Inflammatory Disease Evaluation and Clinical Health $(\mathrm{PEACH})$ study as reported that Chlamydia represents about $14 \%$ of women with chronic endometritis [29].

Some studies put no set of histologic features or degree of intensity of inflammation predicted a particular clinical presentation, a response by the clinician to prescribe antibiotics or outcome [3032]. Also in another study implied that histological examination of an endometrial biopsy is a reproducible method for diagnosis and treatment of CE in asymptomatic patients prior to IVF/ICSI is substantial [33]. Moreover, in patients treated with antibiotics for C. trachamatis, the histological features of endometritis promptly resolves and endometrial cultures become negative [34].
In the current study there was no statistically significant correlation between the incidence of $C$. trachomatis and the age of participants, parity, form of bleeding, history of abortion, type of infertility and duration of marriage. Another study found that Chlamydial endometritis increases as age and parity increase, which was explained due to exposure to infections. This is in partial agreement with our study which found that $\mathrm{CE}$ increases with parity while here was no relation with age [35].

It is stated that there was an association of $\mathrm{CE}$ and salpingitis. It seems that $\mathrm{CE}$ is a marker of an ascending infection, which in younger patients might impair fertility by the presence of salpingitis. A genital tract infection that remains untreated or partially treated or a subclinical ascending infection may progress to cause $\mathrm{CE}$ and possible salpingitis with potential impact on fertility $[36,37]$. This was in accordance with findings from [38] who found in $45 \%$ of cases some pathological finding at diagnostic hysteroscopy prior to IVF most of these abnormalities were endometritis.

Bayer-garner [39] implied that CE was diagnosed in between 3\% and $10 \%$ of women who complaining of abnormal uterine bleeding, also implied that $\mathrm{CE}$ was more common in women who experiencing dysfunctional uterine bleeding. Also, Krettek [40] found that $C$. trachomatis represent 3:5 fold in patients with abnormal uterine bleeding associated CE. This was in contrast with Wiesenfeld [24] study who found no relation between $\mathrm{CE}$ and abnormal uterine bleeding but these findings were limited to sample size and association between $C$. trachomatis and $\mathrm{CE}$.

In one of the first studies on $\mathrm{CE}$, reported that the clinical presentation of patients with $\mathrm{CE}$ was some types of vaginal bleeding [12]. Wiesenfeld reported that, the prevalence of CE was higher in women undergoing hysteroscopy due to abnormal uterine bleeding ( $14.4 \%$ vs $11.7 \%$ ), furthermore, the indications related to bleeding [pre-menopausal abnormal uterine bleeding (AUB), suspected endometrial polyp, endocervical polyp, intracavitary myoma] they were present in up to $36.3 \%$ of cases of CE [24]. There was partial agreement with results of the current study and some studies [41,42], clinical reviews who using PCR to detect $C$. trachomatis in cases of CE. These studies proved that C. trachomatis was associated with severe $\mathrm{CE}$ and dysfunctional uterine bleeding is a common symptom of CE.

\section{Conclusion \& Recommendations}

In view of such findings, the aim of the present work was to detect the prevalence of $C$. trachomatis in symptomatic women complaining of perimenopausal bleeding. The current study documented higher than expected $\mathrm{C}$ trachomatis prevalence in these patients reflecting lack of STI-specific programs in Egypt. Review of these data led to a change of perimenopausal workup policy in our unit, with the introduction of Chlamydia serological screening and antibiotic treatment of positive cases. We hope to use the results of this study to help design and complete larger clinical trials involving the use of endometrial curettings for the detection of Chlamydial antigen by DNA amplification. This may lead to improved identification and characterization of this subgroup of women whose menstrual abnormalities are currently unexplained. 


\section{References}

1. Goldstein SR, Zeltser I, Horan CK. Ultrasonography based triage for perimenopausal patients with abnormal uterine bleeding. Am J Obste Gynecol. 1997; 177: 102-108.

2. Abberton $\mathrm{KM}$, Taylor $\mathrm{NH}$, Healy DL. Vascular smooth muscle alpha-actin distribution around endometrial arterioles during the menstrual cycle: increased expression during the perimenopause and lack of correlation with menorrhagia. Human Reprod. 1996; 11: 204-211.

3. Cadena D, Cavanzo FJ, Leone CL, Taylor HB. Chronic endometritis. A comparative clinicopathologic study. Obstet Gynecol. 1973; 41: 733-738.

4. Farooki MA. Epidemiology and pathology of chronic endometritis. Int Surg 1967; 48: 566-573

5. PaavonenJ, Aine R, Teisala K. Chlamydial endometritis. J Clin Pathol. 1985 38: $726-732$.

6. Johnson RE, Newhall WJ, Papp JR, Knapp JS, Black CM, Gift TL. Screening tests to detect Chlamydia trachomatis and Neisseria gonorrhea infections-2002. MMWR Recomm Rep. 2002; 51: 1-38.

7. Hu D, Hook EW, Goldie SJ. Screening for Chlamydia trachomatis in women 15 to 29 years of age: a cost-effectiveness analysis. Ann Intern Med. 2004 141: 501-513.

8. Carey AJ, Beagley KW. Chlamydia trachomatis a hidden epidemic: effects on female reproduction and treatment. Am J Reprod Immunol. 2010; 63: 576586

9. CDC. Sexually transmitted disease surveillance 2012. Atlanta, GA: US Department of Health and Human Services, CDC; 2013.

10. van Doornum GJ, Schouls LM, Pijl A, Cairo I, Buimer M, Bruisten S Comparison between the LCx Probe system and the COBAS AMPLICOR system for detection of Chlamydia trachomatis and Neisseria gonorrhoeae infections in patients attending a clinic for treatment of sexually transmitted diseases in Amsterdam, The Netherlands. J Clin Microbiol. 2001; 39: 829 835.

11. Smaill F, Hofmeyr GJ. Antibiotic prophylaxis for cesarean section. Cochrane Database Syst Rev. (2002); CD000933. 2008.

12. Greenwood SM, Moran JJ. Chronic endometritis: morphologic and clinical observations. Obstet Gynecol. 1981; 58: 176-184.

13. Jaton K, Bille J, Greub G. A novel real-time PCR to detect Chlamydia trachomatis in first-void urine or genital swabs. J Med Microbiol. 2006; 55 1667-1674.

14. Scottish Intercollegiate Guidelines Network. SIGN. Management of genital Chlamydia trachomatis infection. A national clinical guideline. 2009.

15. Initial investigation and management of the infertile couple. Royal College of Obstetricians and Gynaecologists.

16. Ghazal-Aswad S, Badrinath $\mathrm{P}$, Osman N, Abdul-Khaliq S, Mc Ilvenny S Sidky I. Prevalence of Chlamydia trachomatis infection among women in a Middle Eastern community. BMC Womens Health. 2004; 4: 3 .

17. Al-Ramahi M, Mahafzah A, Saleh S, Fram K. Prevalence of Chlamydia trachomatis infection in infertile women at a university hospital in Jordan. East Mediterr Health J. 2008; 14: 1148-1154.

18. Al-Thani A, Abdul-Rahim H, Alabsi E, Bsaisu HN, Haddad P, Mumtaz GR, et al. Prevalence of Chlamydia trachomatis infection in the general population of women in Qatar. SexTransm Infect. 2013.

19. Kamel RM. Screening for Chlamydia trachomatis infection among infertile women in Saudi Arabia. Int J Womens Health. 2013; 5: 277-284.

20. Cicinelli E, Resta L, Nicoletti R, Marinaccio M, Bulletti C, Colafiglio G, et al. Detection of chronic endometritis at fluid hysteroscopy. J Minim Invasive Gynecol. 2005; 12: 514-518.

21. Kasius JC , Fatemi HM, Devroey P, Frank JM, Broekmans FJ, Sie-Go DM, et al. The impact of chronic endometritis on reproductive outcome. Fertil Steril. 2011; 96: 1959-1965.
22. Cravello L, Porcu G, D'Ercole C, D'Ercole C, Roger V, Blanc B. Identification and treatment of endometritis. Contracept Fertil Sex. 1997; 25: 585-586.

23. Resta L, Palumbo M, Rossi R, Piscitelli D, Grazia Fiore M, Cicinelli E. Histology of micro polyps in chronic Endometritis. Histopathology. 2012; 60; 653-674.

24. Wiesenfeld HC, Sweet RL, Krohn MA, Amortegui A J, Hillier SL. Comparison of acute and subclinical PID. Sex Transm Dis. 2005; 32: 400-405.

25. Wei HB, Zou SX, Yang XL, Chen XD. Development of multiplex real -time quantitative PCR for simultaneous detection of Chlamydia trachomatis and Ureaplasma parvum. J. Clin Biochem. 2012; 45: 663-667.

26. Watson ED, Thomson SR: Lymphocyte subsets in endometrium of genital normal mares and mares susceptible to endometritis. Equine Vet J. 1996; 28: $106-110$.

27. Tobin JM, Harinda V, Mani R. Which treatment for genital tract Chlamydia trachomatis infection? Int J STD AIDS. 2004; 15: 737-739

28. Cicinelli E, De Ziegler D, Nicoletti R. Chronic endometritis: Correlation among hysteroscopic, histologic and bacteriologic findings in a prospective trial with 2190 consecutive office hysteroscopies. Fertil Steril. 2008; 89: 677-684.

29. Stern RA, Svoboda-Newman SM, Frank TS. Analysis of chronic endometritis for C. trachomatis by polymerase chain reaction. Hum Pathol. 1996; 27: 1085-1088

30. Crum CP, Hornstein MD, Stewart EA. Evaluation of cyclic endometrium and benign endometrial disorders. In: Crum CP, Lee KR, eds. Diagnostic Gynecologic and Obstetric Pathology. 1st ed. Philadelphia, PA: Elsevier Saunders. 2008; 53: 441-491.

31. Ross JDC. What is endometritis, does it require treatment? Sex Transm Inf 2004; 80: 252-253

32. Crossman S. The challenge of pelvic inflammatory disease. Am Fam Physician. 2006; 73: 859-864.

33. Kasius JC, Broekmans FJ, Fauser P, Fatemi HM. The reliability of the histological diagnosis of endometritis in asymptomatic IVF cases :a multicenter observe study. Hum Reprod. 2012; 27: 153-158.

34. Gump DW, Dickstein S, Gibson M. Endometritis related to Chlamydia trachomatis infection. Ann intern Med. 1981; 95: 61-63.

35. Zolghadri J, Momtahan M, Aminian K, Ghaffarpasand F, Tavan Z. The value of hysteroscopy in diagnosis of chronic endometritis in patients with unexplained recurrent spontaneous abortion. Euro.J.Obste Gynecol. 2011; 155: $217-220$.

36. Pitsos M, Skurnick J, Heller D. Association of Pathologic Diagnosis with Clinical Findings in Chronic Endometritis. Reproductive med J. 2009; 54 : 373-377.

37. Taylor S, Frydman R .Hysteroscopy and sperm infection. J Reprod Med. 1996; 24: 359-389.

38. Feghali J, Bakar J, Mayenga JM, Segard L, Hamou J, Driguez P. Systematic hysteroscopy prior to in IVF. Gynecol Obstet Fertil. 2003; 31: 127-131.

39. Bayer-Garner I, Nickell J, Korourian S. Routine syndecan-1 immunochemistry aids in diagnosis of endometritis. Arch Pathol Lab Med. 2004; 128: 1000 1003.

40. Krettek J, Arkin S, Chaisilwattana P, Monif GR. Chlamydia in patients who used oral contraceptives and had intermenstrual spotting. Obstet Gynecol. 1993; 81: 728-731.

41. Winkler B, Reumann W, Mitao M. Chlamydial endometritis:A histological and immunohistochemical analysis. Am J Surg Pathol. 1984; 8: 771-778.

42. Mardh PA, Wolner - Hansseen P: Three novel manifestations of Chlamydia trachomatis infection: Endometritis, Perihepatitis and meningoencephalitis. Infection. 1982; 10: S57-60. 